\title{
Clostridium botulinum Type B Isolated From a Wound Botulism Case Due to Injection Drug Use Resembles Other Local Strains Originating From Hawaii
}

\author{
Jessica L. Halpin*, Victoria Foltz, Janet K. Dykes, Kevin Chatham-Stephens and \\ Carolina Lúquez
}

Centers for Disease Control and Prevention, Atlanta, GA, United States

OPEN ACCESS

Edited by:

Fabrizio Anniballi,

Sanità Pubblica Veterinaria e Sicurezza Alimentare, Istituto

Superiore di Sanità, Italy

Reviewed by:

Sabine Pellett,

University of Wisconsin-Madison,

United States

Concetta Scalfaro,

National Institute of Health (ISS), Italy

*Correspondence:

Jessica L. Halpin

JLHalpin@cdc.gov

Specialty section: This article was submitted to

Evolutionary and Genomic Microbiology

a section of the journal Frontiers in Microbiology

Received: 09 March 2021 Accepted: 09 June 2021 Published: 22 July 2021

Citation:

Halpin JL, Foltz V, Dykes JK Chatham-Stephens $K$ and Lúquez $C$ (2021) Clostridium botulinum Type $B$

Isolated From a Wound Botulism Case Due to Injection Drug Use Resembles Other Local Strains

Originating From Hawaii.

Front. Microbiol. 12:678473. doi: 10.3389/fmicb.2021.678473
Clostridium botulinum produces botulinum neurotoxin (BoNT), which can lead to death if untreated. In the United States, over $90 \%$ of wound botulism cases are associated with injection drug use of black tar heroin. We sought to determine the phylogenetic relatedness of $C$. botulinum isolated from an injection drug use wound botulism case and isolates from endogenous infant botulism cases in Hawaii. Nineteen C. botulinum type B isolates from Hawaii and one type B isolate from California were analyzed by whole-genome sequencing. The botulinum toxin gene (bont) subtype was determined using CLC Genomics Workbench, and the seven-gene multi-locus sequence type (MLST) was identified by querying PubMLST. Mashtree and pairwise average nucleotide identity were used to find nearest neighbors, and Lyve-SET approximated a phylogeny. Eighteen of the isolates harbored the bont/B5 gene: of those, 17 were classified as sequence type ST36 and one was classified as ST104. A single isolate from Hawail harbored bont/B1 and was determined to belong to ST110, and the isolate from California harbored bont/B1 and belonged to ST30. A tree constructed with LyveSET showed a high degree of homology among all the Hawaiian C. botulinum isolates that harbor the bont/B5 gene. Our results indicate that the bont/B-expressing isolates recovered from Hawaii are closely related to each other, suggesting local contamination of the drug paraphernalia or the wound itself with spores rather than contamination of the drug at manufacture or during transport. These findings may assist in identifying interventions to decrease wound botulism among persons who inject drugs.

Keywords: wound botulism, bont/B5, BoNT, Clostridium botulinum, heroin use, skin popping, injection drug use

\section{INTRODUCTION}

Botulism is a life-threatening disease caused by botulinum neurotoxins (BoNT) which are produced by Clostridium botulinum and rare strains of Clostridium butyricum and Clostridium baratii. C. botulinum is an anaerobic spore-forming bacterium commonly found in soil. Currently, there are seven well-characterized serotypes for BoNT $(A-G)$, classically determined by polyclonal 
antibody neutralization assays (Hill et al., 2007). Additional serotypes have been proposed (BoNT/X,/En, and/H) but have not yet reached consensus within the scientific community (Barash and Arnon, 2014; Mansfield et al., 2015; Brunt et al., 2018; Popoff, 2018). BoNT are encoded by the bont gene, which is part of a cluster with a regulator $($ bot $R$ ), and non-toxic accessory genes: non-toxic non-hemagglutinin $(n t n h)$ and either open reading frame $\mathrm{X}(\operatorname{orf} \mathrm{X})$ or hemagglutinin (HA) genes (Rossetto et al., 2014). BoNT serotypes can have multiple gene subtypes, which are determined by differences in the amino acid sequence. Over 40 subtypes of BoNT serotypes A, B, E, and F have been identified to date (Peck et al., 2017). Serotypes A and B cause most human botulism cases within the United States.

Botulinum neurotoxins are metalloproteases that target motor neurons, preventing the release of acetylcholine at neuromuscular junctions, which can lead to a flaccid paralysis (Rossetto et al., 2014). There are four naturally occurring forms of human botulism: infant botulism, foodborne intoxication, wound colonization, and adult intestinal colonization. Infant botulism is the most common form of the disease within the United States. It occurs when a baby under 1 year of age ingests $C$. botulinum spores, most likely by swallowing dust particles that carry locally acquired spores; the spores then germinate within the intestinal tract and produce BoNT in situ [Chin et al., 1979; Centers for Disease Control and Prevention (CDC), 1998]. Foodborne botulism occurs when food becomes contaminated with pre-formed BoNT and is ingested [Centers for Disease Control and Prevention (CDC), 1998]. Wound botulism occurs when C. botulinum spores enter a wound or necrotic tissue; the spores germinate, multiply, and release BoNT [Centers for Disease Control and Prevention (CDC), 1998]. A very rare form of the disease, adult intestinal colonization, occurs when an adult becomes colonized with C. botulinum spores, which germinate and produce BoNT in situ [Centers for Disease Control and Prevention (CDC), 1998].

CDC, in partnership with state and local public health laboratories, endeavors to conduct a surveillance for every confirmed case of botulism in the United States. Botulism has been a nationally required notifiable disease since 1947 , and a case is confirmed when toxin is detected in clinical samples (e.g., serum, stool) or a suspected food sample or when C. botulinum organisms are isolated from a stool sample ${ }^{1}$. CDC's National Botulism Laboratory serves as a reference laboratory, a central testing laboratory for states that do not do botulism testing, and an overflow laboratory for states who may typically conduct their own botulism testing but require assistance due to capacity or other needs.

The Centers for Disease Control and Preventions' surveillance data from 1981 to 2016 totals 4,807 laboratory-confirmed cases of botulism within the United States ${ }^{2}-70 \%$ infant botulism, $11 \%$ wound botulism, and 19\% foodborne or "other" (adult intestinal colonization or unknown route of transmission). Once a rare form of the disease, wound botulism has become more common in the United States starting in the 1990s with the increased use of

${ }^{1}$ https://wwwn.cdc.gov/nndss/conditions/botulism/case-definition/2011/ black tar heroin (BTH) (Passaro et al., 1998; Werner et al., 2000; Davis and King, 2008; Peak et al., 2019). From 1981 to 2016, there was an average of 15 wound botulism cases per year. During this 35 -year period, $74.6 \%$ of wound botulism cases were due to injection drug use, and $25.4 \%$ of wound cases were associated with other types of trauma (e.g., lacerations, abscesses, necrotic tissue, gunshot wounds, or unknown) $)^{2}$.

Users of heroin, particularly those who inject subcutaneously (i.e., skin popping), have a higher incidence of wound botulism. Skin popping can create an anaerobic environment under the skin, which facilitates the germination and release of BoNT. Because it is linked to skin popping, black tar heroin is the suspected source of C. botulinum spores. Currently, it is unknown exactly how BTH becomes contaminated with C. botulinum spores, but there are many opportunities: the drug is often cut with other substances, the drug travels long distances from source to user, the use of dirty needles or equipment, and the drug may be manipulated by the user prior to injection (Davis and King, 2008). Culturing C. botulinum from BTH is challenging, as it has a sticky composition that makes it difficult to solubilize in buffers and standard culture media. One of the major challenges for testing BTH is that, because it is a schedule I controlled substance by the United States Drug Enforcement Agency (DEA), a laboratory intending to perform microbiological testing of heroin requires a DEA license and adherence to a strict chain of custody and inventory documentation (United States Department of Justice Drug Enforcement Administration Office of Diversion Control, 2006).

The CDC's National Botulism Laboratory received isolates from a wound botulism case in Hawaii for confirmation testing. The patient had a history of BTH use, specifically via skin-popping daily for 2 weeks prior to hospital admittance. Due to the patient's history, it is believed that the wound botulism occurred from injection drug use. Based on publicly available CDC surveillance data ${ }^{2}$, this was the first reported laboratory-confirmed case of wound botulism from Hawaii. The isolates were confirmed as C. botulinum serotype B. Our analysis of CDC surveillance data for the United States between 1981 and 2016 showed that about 77\% $(n=420)$ of reported wound cases in the United States were due to serotype A, $12 \%(n=65)$ were attributed to serotype $\mathrm{B}$, and $11 \%$ did not have a serotype reported $(n=61)$ (9). Due to the novel report of wound botulism from Hawaii, the isolated geography of the case, and the rarity of serotype B wound botulism, we sought to determine whether the C. botulinum type B isolated from this wound botulism case resembled other C. botulinum type B isolates from infant botulism cases (approximately $0-4$ confirmed cases per year, 1981-2016) in Hawaii (Nevas et al., 2005). C. botulinum isolates from infant cases were chosen, as it has been long recognized to be caused by spores from the local environment which become ingested by babies under 1 year old [Centers for Disease Control and Prevention (CDC), 1998]. As a result, these isolates could be considered representative of the local geography in which they occur.

\footnotetext{
${ }^{2}$ http://www.cdc.gov/nationalsurveillance/botulism-surveillance.html
} 
A single C. botulinum type B isolate from an infant botulism case in California, United States, was included, as it is a common thoroughfare for travel to Hawaii, and it was the geographically closest serotype B environmental isolate found within our collection.

\section{MATERIALS AND METHODS}

\section{Microbiology}

The strains used in this study are described in Table 1. We recovered each strain from long-term storage by inoculating $0.5-$ $1.0 \mathrm{ml}$ of sporulation media $(20 \mathrm{~g} / \mathrm{L}$ peptone, Difco, Franklin Lakes, NJ, United States; beef brain, Pel-Freez Biologicals; Rogers, AR, United States) into chopped meat glucose starch broth (CMGS) (Remel; Lenexa, KS, United States), and each grew in a Coy (Grass Lake, MI, United States) anaerobic chamber at $35 \pm 2^{\circ} \mathrm{C}$ for $24-48 \mathrm{~h}$. We examined CMGS cultures for growth and quadrant streaked $\sim 0.5 \mathrm{ml}$ of CMGS culture for isolation onto McClung Toabe egg yolk agar with yeast extract agar plates (McClung Toabe agar base, $75 \mathrm{~g} / \mathrm{L}$; yeast extract, $5 \mathrm{~g} / \mathrm{L}$; egg yolk enrichment, $100 \mathrm{ml} / \mathrm{L}$-all from Difco, Franklin Lakes, NJ, United States). The plates grew anaerobically at $35 \pm 2{ }^{\circ} \mathrm{C}$ for $24-48 \mathrm{~h}$ and were examined for purity. We picked single colonies that exhibited lipase activity and inoculated them into trypticase peptone glucose yeast extract broth (TPGY) (Remel, Lenexa, KS, United States). These cultures grew anaerobically at $35 \pm 2{ }^{\circ} \mathrm{C}$ for $16-24 \mathrm{~h}$ prior to genomic DNA extraction.

\section{Genomic DNA Extraction}

We used a modified Epicenter (Madison, WI, United States) MasterPure Complete DNA and RNA Purification kit to extract genomic DNA from 8 to $9 \mathrm{ml}$ of turbid TPGY culture. Briefly, cells were pelleted at $4 \pm 1^{\circ} \mathrm{C}$ for $10 \mathrm{~min}$ at $4,000 \mathrm{rpm}$, and the supernatant was discarded. We resuspended cell pellets in lysozyme stock solution (25 mM Tris- $\mathrm{HCl}, \mathrm{pH}$ 8.0, Invitrogen, Waltham, MA, United States; $2.5 \mathrm{mM} 0.5 \mathrm{M}$ EDTA, Invitrogen, Waltham, MA, United States; $10 \mathrm{ml}$ Triton X-100, Sigma, St. Louis, MO, United States; and $20 \mathrm{mg} / \mathrm{ml}$ lysozyme from chicken egg white, Sigma, St. Louis, MO, United States) and incubated them for a minimum of $15 \mathrm{~min}$ in a $37 \pm 1^{\circ} \mathrm{C}$ water bath. We added $300 \mu \mathrm{l}$ of undiluted 2X T\&C buffer (Epicenter, Madison, WI, United States) and $3 \mu \mathrm{l}$ of RNase A (Qiagen, Redwood City, CA, United States) to the cell suspension, gently mixed it, and then incubated it in a $57 \pm 1^{\circ} \mathrm{C}$ water bath for $10 \mathrm{~min}$. To this mixture, we added $3 \mu \mathrm{l}$ of Proteinase K (Invitrogen, Waltham, MA, United States) and incubated it in the water bath for another $10 \mathrm{~min}$ at $57 \pm 1^{\circ} \mathrm{C}$. After incubation with proteinase, we added $350 \mu \mathrm{l}$ of MPC protein precipitation buffer (Epicenter, Madison, WI, United States) to the solution and centrifuged it at 4,000 rpm at $4 \pm 1^{\circ} \mathrm{C}$ for $10 \mathrm{~min}$. We collected the supernatants and added each to $1 \mathrm{ml}$ of $99 \%$ isopropanol to precipitate the DNA. We collected the precipitates, washed them with $1 \mathrm{ml}$ of $70 \%$ ethanol, and rehydrated them at least overnight (up to 1 week) in $200 \mu \mathrm{l}$ of $10 \mathrm{mM}$ Tris- $\mathrm{HCl}$ (Invitrogen, Waltham, MA, United States). We filtered the rehydrated gDNA through $0.1-\mu \mathrm{M}$ centrifugal filters (MilliporeSigma, Burlington, MA, United States) to remove any spores or unlysed cells. We used the Nanodrop 2000 (NanoDrop

TABLE 1 | Summary of Clostridium botulinum producing toxin serotype B strains used in this study: year isolated, botulism type, originating state, specimen source, toxin subtype, and seven-gene multi-locus sequence type (MLST).

\begin{tabular}{|c|c|c|c|c|c|c|}
\hline Isolate ID \# & Year & $\begin{array}{l}\text { Botulism } \\
\text { type }\end{array}$ & State & $\begin{array}{c}\text { Specimen } \\
\text { type }\end{array}$ & $\begin{array}{c}\text { Toxin } \\
\text { subtype }\end{array}$ & $\begin{array}{c}\text { Seven-gene } \\
\text { MLST }\end{array}$ \\
\hline CDC21601 & 1976 & Infant & $\mathrm{CA}$ & Stool & B1 & 30 \\
\hline CDC31747 & 1986 & Infant & HI-Oahu & Stool & B5 & 36 \\
\hline CDC34293 & 1989 & Infant & HI-Maui & Stool & B5 & 36 \\
\hline CDC36757 & 1981 & Infant & HI-Oahu & Stool & B5 & 36 \\
\hline CDC37391 & 1982 & Infant & HI-Oahu & Stool & B5 & 36 \\
\hline CDC38839 & 1983 & Infant & HI-Oahu & Stool & B5 & 36 \\
\hline CDC39168 & 1984 & Infant & HI-Maui & Stool & B5 & 36 \\
\hline CDC40176 & 1995 & Infant & HI-Oahu & Stool & B5 & 36 \\
\hline CDC41623 & 1996 & Infant & HI-Oahu & Stool & B5 & 36 \\
\hline CDC45459 & 1990 & Infant & HI-Maui & $\begin{array}{l}\text { Stool- } \\
\text { enema }\end{array}$ & B5 & 36 \\
\hline CDC47455 & 1992 & Infant & HI-Maui & Stool & B5 & 36 \\
\hline CDC48611 & 1993 & Infant & HI-Kaua'i & Stool & B1 & 110 \\
\hline CDC49917 & 1994 & Infant & HI-Oahu & Stool & B5 & 36 \\
\hline CDC53044 & 2008 & Infant & HI-Maui & Stool & B5 & 36 \\
\hline CDC54117 & 2009 & Infant & HI-Oahu & Stool & B5 & 36 \\
\hline CDC54250 & 2009 & Infant & HI-Oahu & Stool & B5 & 36 \\
\hline CDC59947 & 2004 & Infant & HI-Maui & Stool & B5 & 36 \\
\hline CDC60225 & 2015 & Infant & HI-Hawaii & Stool & B5 & 36 \\
\hline CDC61035 & 2016 & Wound & HI-Oahu & Wound & B5 & 36 \\
\hline CDC65069 & 2010 & Infant & HI-Maui & Stool & B5 & 104 \\
\hline
\end{tabular}


Technologies, Wilmington, DE, United States) and the Qubit 4 (Invitrogen, Waltham, MA, United States) fluorometer highsensitivity assay to assess genomic DNA quality and quantity according to the manufacturers' instructions.

\section{Whole-Genome Shotgun Sequencing}

We constructed barcoded shotgun libraries using NextFlex DNA barcodes (BIOO Scientific, Austin, TX, United States) and the 400-bp Kapa Biosciences (Wilmington, MA, United States) kit for Ion Torrent chemistry (KAPA Biosystems, 2016). We performed size selection using the e-gel system to select for 500-bp fragments (Life Technologies, 2017). We diluted and pooled completed libraries to obtain an equimolar concentration of $200 \mathrm{pM}$ and then templated and enriched using the Ion Chef instrument (Life Technologies), followed by sequencing on Ion Torrent S5 (Life Technologies, 2019).

\section{Bioinformatics and Quality Control}

We assessed read quality using FastQC v.0.11.5 (Andrews, 2014) and assembled reads using SPAdes v.3.10.1 with the following parameters set: sc, iontorrent, single end, and careful (Bankevich et al., 2012). We assessed the resulting assemblies with Quast v.4.3 (Gurevich et al., 2013). We used the map reads to reference tool in CLC Genomic Workbench v.10.1.1 to determine toxin gene subtypes as well as identify accessory genes HA, BotR, and ntnH. We identified the legacy sevengene multi-locus sequence types (MLST) by querying draft genomes against the PubMLST (Jacobson et al., 2008) database with the Center for Genomic Epidemiology website ${ }^{3}$. We used Mashtree v.0.37 (Katz et al., 2019) to determine pairwise mash distances (Ondov et al., 2016) and place the isolates in a neighbor-joining tree of reference sequences and other serotype $\mathrm{B}$ sequences from the CDC short read sequence collection. We used pairwise average nucleotide identity (ANI) (Goris et al., 2007) to identify the closest reference sequences as well as to compare pairwise sequence homologies. We identified the nearest neighbor by ANI, and this reference sequence was used in Lyve-SET v.1.1.4f (Katz et al., 2017) to determine highquality single-nucleotide polymorphism (hqSNP) sites across the study sequences and then draw a tree with bootstrap support to approximate a phylogeny (Lyve-SET settings enabled: single end, allowed Flanking 5, min_alt_frac 0.75, min_coverage 10, mask-phages, mask-cliffs, read_cleaner $=$ CGP, mapper $=$ smalt $)$. Using these settings, Lyve set defines high-quality SNPs as those in regions of contiguous coverage of at least 10 , present in at least $75 \%$ of the reads, and not in known phage sequences.

\section{Data Availability}

The Short Read Archive accession numbers are as follows: SHBZ00000000, SHCA00000000, SHCB00000000, SHCC00 000000, SHCD00000000, SHCE00000000, SHCF00000000, SHCG00000000, SHCH00000000, SHCI00000000, SHCJ00 000000, SHCK00000000, SHCL00000000, SHCM00000000,

\footnotetext{
${ }^{3}$ http://www.genomicepidemiology.org/
}

SHCN00000000, SHCO00000000, SHCP00000000, SHCQ00 000000, SHCR00000000, and SHCS00000000.

\section{RESULTS}

The resulting number of reads, GC content, and estimated genome size are found in Table 2 . The number of resulting reads was 227,559 to $2,461,814$; GC content ranged from 27.7 to $28.0 \%$; reads assembled into 35-257 contigs; N50s ranged from 26,682 to 277,264; average coverage ranged from $20.4 \times$ to $227.7 \times$; and approximate assembled genome size was 3.9 to 4.2 mega-bases. Subtypes of Hawaii C. botulinum infant or wound isolates were determined to be bont/B5 $(n=18)$ and bont/B1 $(n=1)$, with an average coverage across the gene of $23 \times$ (3$51 \times)$. Querying the PubMLST database, which generates an allelic profile or seven-gene MLST sequence type (ST), revealed that the strains harboring bont/B5 gene were all members of ST-36 except one, which was ST-104. The C. botulinum isolate from Hawaii harboring bont/B1 gene was a member of ST-110, and the C. botulinum isolate from California harboring a bont/B1 gene was a member of ST-30 (Table 1).

Mashtree placed the C. botulinum bont/B5 isolates from Hawaii into a single cluster, distant from bivalent strains and other strains that harbor the bont/B5 gene (Figure 1). The sole California isolate as well as the isolate from Hawaii harboring bont/B1 were members of the bont/B1 cluster. ANI corroborated the mashtree results by identifying CDC67071 (RefSeq accession numbers NZ_CP013242.1 and NZ_CP013241.1) as the closest closed reference strain to the Hawaii cluster and verifying that the C. botulinum type B isolates from Hawaii are more closely related to each other than to other isolates tested by pairwise ANI.

We used Lyve-SET with CDC67071 as the reference to approximate a phylogeny of the $C$. botulinum isolates from Hawaii that harbor bont/B5 (Figure 2). Lyve-SET used 10,424 hqSNP sites to approximate a phylogeny which resulted in 4-10,103 pairwise hqSNP differences between the sequences. Within this tree, two clades formed: clade 1 containing CDC65069 (ST-104, harboring bont/B5 gene) from an infant botulism case and clade 2 containing CDC31747, CDC34293, CDC36757, CDC37391, CDC38839, CDC38168, CDC40176, CDC41623, CDC45459, CDC47455, CDC49917, CDC53044, CDC54117, CDC54250, CDC59947, CDC60225, and CDC61035 (wound isolate). Clade 2 contains the remainder of the bont/B5 isolates from Hawaii, all belonging to ST36 and all from infant cases except for the single wound botulism isolate (as noted). Clade 1 is separated from clade 2 by 10,103 hqSNP differences, and 4-29 hqSNP differences are found within clade 2.

For these 18 C. botulinum type B isolated from botulism cases from Hawaii, the bont/B5 gene is located on a plasmid. We found nothing notable about the hemagglutinins or the bot $\mathrm{R}$ gene, but the ntnh gene has a 39-bp insert. This insertion was not in the $n t n h$ gene of isolates harboring bont/B1 that we investigated herein nor in reference strains Okra, CDC67071, CDC69094, or CDC1436. This addition does not disrupt the frame of the gene. 
TABLE 2 | Summary of the sequencing statistics for Clostridium botulinum strains isolated from infant and wound botulism cases in Hawaii and California.

\begin{tabular}{|c|c|c|c|c|c|c|c|c|c|c|}
\hline Isolate ID \# & GC (\%) & \# contigs & $\begin{array}{c}\text { Largest } \\
\text { contig (bp) }\end{array}$ & $\begin{array}{c}\text { Total } \\
\text { length (bp) }\end{array}$ & N50 (bp) & \# reads & $\begin{array}{c}\text { Average } \\
\text { read } \\
\text { length }(b p)\end{array}$ & $\begin{array}{l}\text { Average } \\
\text { coverage }\end{array}$ & $\begin{array}{l}\text { \# reads } \\
\text { mapping } \\
\text { to bont }\end{array}$ & $\begin{array}{c}\text { Average } \\
\text { coverage } \\
\text { across bont }\end{array}$ \\
\hline CDC21601 & 28.0 & 55 & 686,068 & 3,978,905 & 277,264 & $1,916,257$ & 284 & 143.2 & 965 & 69.31 \\
\hline CDC31747 & 27.7 & 64 & 594,898 & $4,15,0368$ & 224,881 & $2,461,814$ & 293 & 180.3 & 649 & 44.26 \\
\hline CDC34293 & 27.7 & 85 & 594,976 & $4,227,167$ & 118,018 & $1,593,628$ & 293 & 116.7 & 333 & 23.02 \\
\hline CDC36757 & 27.7 & 35 & 653,290 & $4,156,210$ & 255,842 & $2,567,944$ & 337 & 227.7 & 642 & 50.47 \\
\hline CDC37391 & 27.7 & 79 & 278,989 & 4,139,909 & 128,587 & 522,334 & 333 & 45.8 & 120 & 9.36 \\
\hline CDC38839 & 27.7 & 41 & 501,509 & $4,158,619$ & 301,466 & 849,846 & 307 & 68.7 & 209 & 15.24 \\
\hline CDC39168 & 27.8 & 193 & 177,384 & 4,141,306 & 46,127 & 895,235 & 282 & 63.1 & 158 & 10.25 \\
\hline CDC40176 & 27.7 & 116 & 416,804 & $4,158,067$ & 75,335 & 626,019 & 207 & 32.4 & 61 & 3.24 \\
\hline CDC41623 & 27.7 & 59 & 540,802 & $4,217,736$ & 194,214 & $1,283,745$ & 227 & 72.9 & 368 & 20.62 \\
\hline CDC45459 & 27.7 & 87 & 322,199 & $4,198,117$ & 111,949 & $2,068,237$ & 254 & 131.3 & 498 & 29.75 \\
\hline CDC47455 & 27.7 & 80 & 273,668 & $4,199,837$ & 114,010 & 1,361,983 & 262 & 89.2 & 310 & 19.07 \\
\hline CDC48611 & 28.0 & 122 & 253,643 & $3,843,066$ & 53,585 & 624,594 & 274 & 42.8 & 286 & 18.95 \\
\hline CDC49917 & 27.7 & 252 & 104,953 & $4,163,377$ & 26,682 & 757,736 & 200 & 37.9 & 888 & 44.96 \\
\hline CDC53044 & 27.8 & 86 & 587,411 & 4,331,526 & 225,901 & $1,788,944$ & 308 & 137.7 & 452 & 33.91 \\
\hline CDC54117 & 27.7 & 97 & 213,589 & $4,203,614$ & 90,518 & 648,044 & 232 & 37.6 & 172 & 9.66 \\
\hline CDC54250 & 27.7 & 257 & 148,760 & $4,162,820$ & 32,556 & 227,559 & 340 & 20.4 & 43 & 3.51 \\
\hline CDC59947 & 27.7 & 131 & 215,257 & $4,187,706$ & 65,567 & 615,768 & 273 & 42.0 & 181 & 12.55 \\
\hline CDC60225 & 27.7 & 68 & 439,777 & 4,333,055 & 142,003 & $1,031,444$ & 334 & 90.7 & 254 & 12.63 \\
\hline CDC61035 & 27.7 & 78 & 430,766 & $4,153,245$ & 133,216 & 845,541 & 288 & 60.9 & 209 & 13.69 \\
\hline CDC65069 & 27.7 & 41 & 636,062 & $4,186,206$ & 255,806 & 896,025 & 334 & 78.8 & 227 & 15.53 \\
\hline
\end{tabular}

\section{DISCUSSION}

The results herein suggest that the heroin that is presumed to be the causative agent of wound botulism was contaminated with C. botulinum spores locally rather than in manufacturing or transit. This was the first reported wound case from Hawaii and was confirmed in the laboratory as toxin type B. The CDC surveillance data (1981-2016) reports a total of 61 confirmed cases of botulism from Hawaii (53 infant botulism, seven foodborne botulism, and one wound botulism). Serotype B was confirmed for 56 out of the 61 total cases; the remaining five were infant botulism cases due to serotype $\mathrm{A}^{\mathrm{N} 1}$.

Black tar heroin was first introduced into the United States from Mexico in the 1970s and was predominantly used in California. According to the Hawaii Drug Threat Assessment, the main distribution hub for BTH to Hawaii is through Los Angeles, CA (National Drug Intelligence Center, 2002). Heroin is typically cut where it is distributed; however, it is still unclear if contamination with C. botulinum spores occurs from local or distant geographic sources (Passaro et al., 1998; Werner et al., 2000; Peak et al., 2019).

Because of the high number of type B botulism cases in Hawaii, we had the opportunity to select and compare 18 C. botulinum type B isolates from the CDC strain collection associated with infant botulism. These isolates were selected for this study to aid in determining if this C. botulinum type B isolate from a wound botulism case is phylogenetically related to other locally acquired Hawaiian C. botulinum isolates. Infants may acquire C. botulinum spores by swallowing dust particles, and thus C. botulinum isolated from infant botulism cases can be viewed as environmental representatives of endogenous strains (Nevas et al., 2005; Fleck-Derderian et al., 2017). We also included a California C. botulinum type B isolate because the import path for BTH to Hawaii is through California. This isolate is also the only "environmentally acquired" C. botulinum type B isolate from the west coast in the CDC historic strain collection.

Eighteen out of the 19 C. botulinum type B isolates from botulism cases from Hawaii harbored the bont/B5 gene, including the wound isolate (CDC61035). Previous studies investigating C. botulinum genetic diversity (Hill et al., 2007; Luquez et al., 2009; Williamson et al., 2016) indicate that a large portion of bont/B5-harboring strains has been identified in bivalent strains (types $\mathrm{Ab}, \mathrm{Ba}$, and $\mathrm{Bf}$ ) or type $\mathrm{A}$ isolates that harbor a silent $\mathrm{B}$ gene [designated as $\mathrm{A}(\mathrm{B})$ strains]. These earlier studies indicate that $A(B)$ strains typically cluster together due to their highly conserved sequences, and bivalent strains display more variability within their sequences; however, they still cluster closely. It is known that the bont/B5 gene can be found alone (Franciosa et al., 2009; Kenri et al., 2014), and our observation is that the occurrence of bont/B5 with no other toxin gene present is more common than once thought (unpublished observations). Williamson et al. (2016) reported that a C. botulinum type B strain that harbors only a bont/B5 gene still clusters closely to bivalent strains in core genome phylogenies. There have not been extensive studies published studying the evolution of C. botulinum strains over time as they persist in the environment.

For these 18 C. botulinum type B isolated from botulism cases from Hawaii, the bont/B5 gene is located on a plasmid. Each of the contigs containing the bont gene was compared against the NCBI nucleotide database using blastn, and the group most 


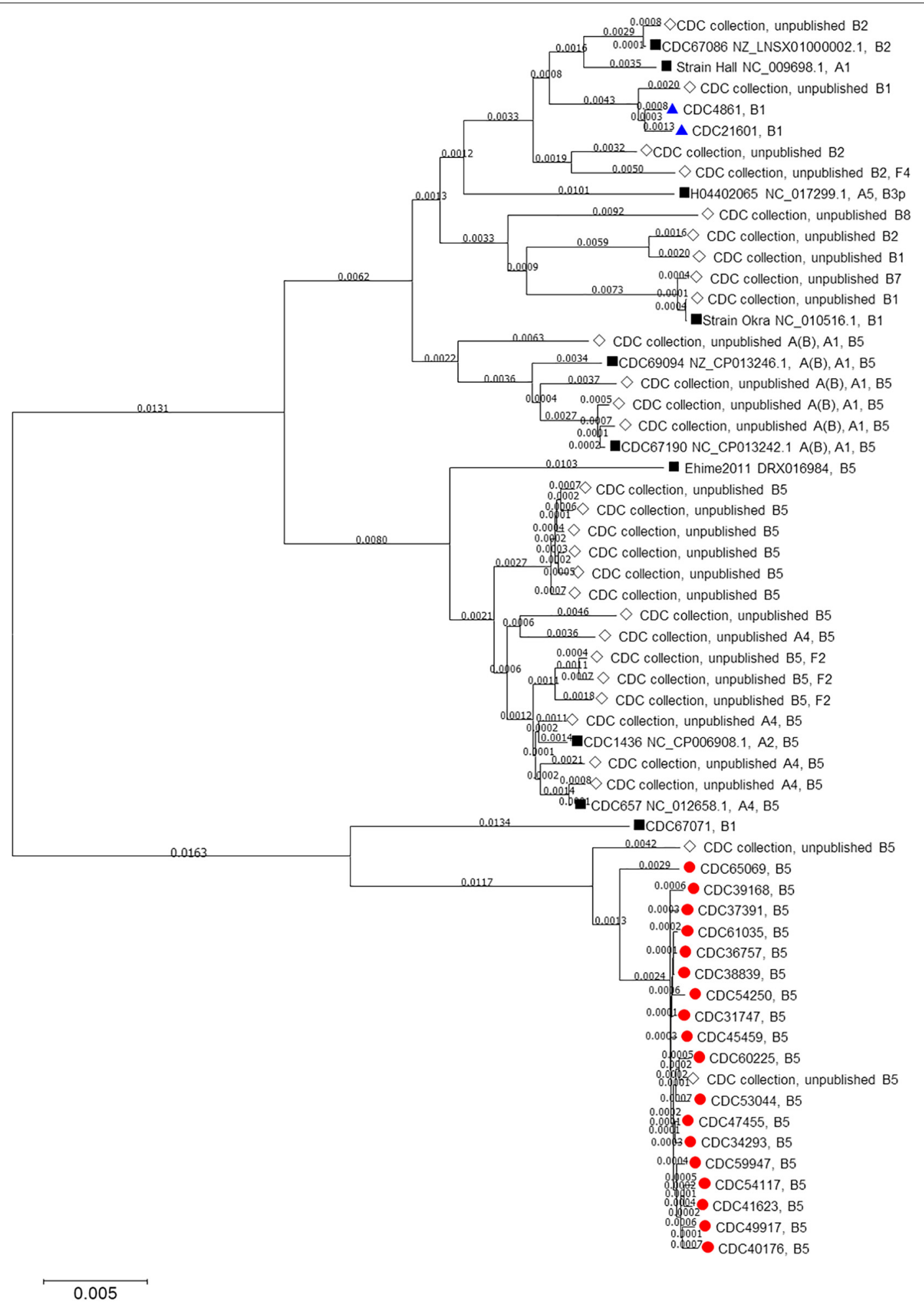

FIGURE 1 | Neighbor-joining tree drawn using MASH distances. The tree includes Clostridium botulinum isolates harboring bont/B5 (red circles) and bont/B1 (blue triangles) genes as described in Table $\mathbf{1}$ as well as NCBI reference sequences (black squares) and other unpublished isolates from the CDC collection (white diamonds). 

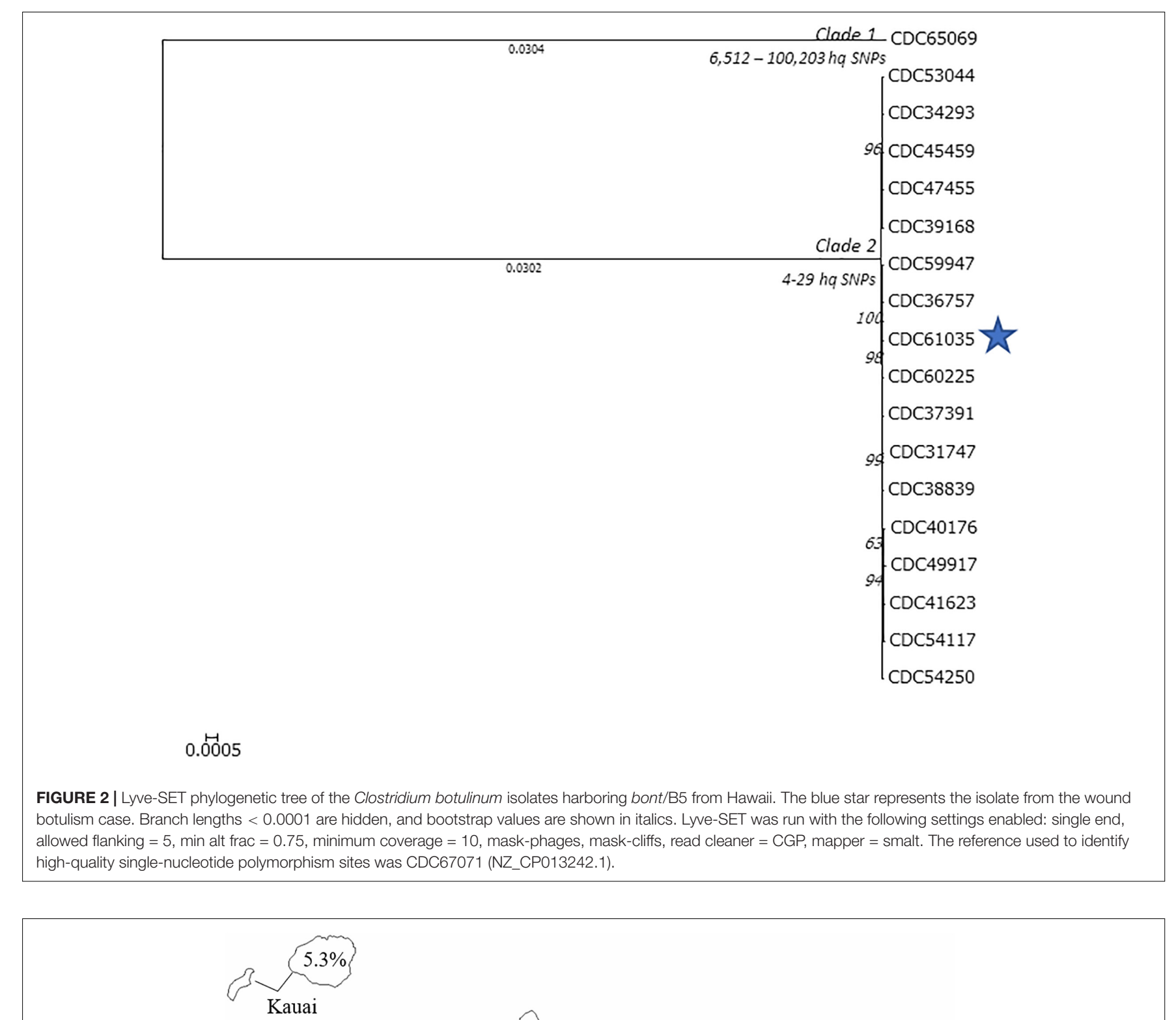

Kauai

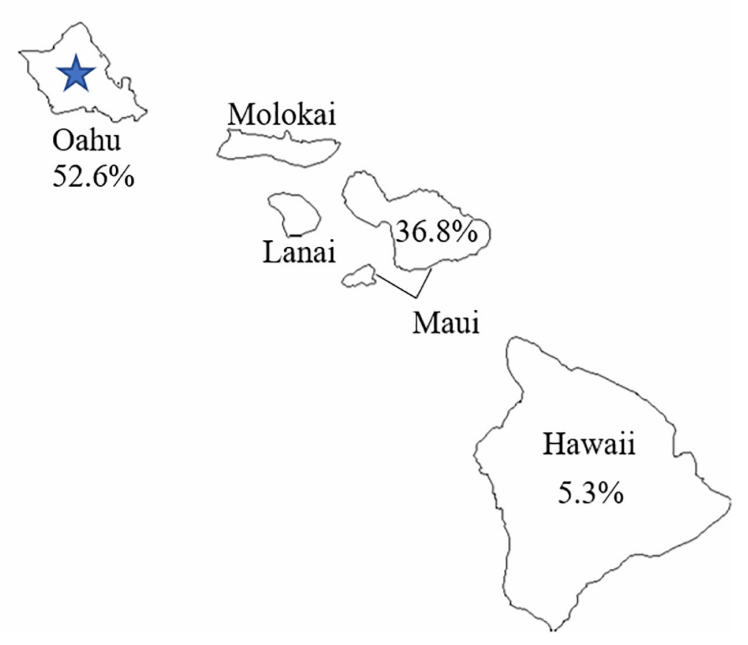

FIGURE 3 | Geographic distribution of Clostridium botulinum type B used in this study. The blue star represents the reported origin of the wound botulism case. 
closely resembled pCLJ from bivalent strain CDC657, which harbors the bont/A4 and bont/B5 genes. There was nothing notable about most of the accessory genes (hemagglutanins and BotR), but there is a 39-bp insert in the ntnh gene that will not disrupt the reading frame. This insertion is also present in C. botulinum strain CDC657 bont/B-associated ntnh gene (accession \#EU341304) but not in the ntnh gene of isolates harboring bont/B1 that we investigated herein nor in reference strains Okra, CDC67071, CDC69094, or CDC1436. This addition does not disrupt the frame of the gene, allowing a fully functional protein to be produced.

A neighbor-joining tree (Figure 1) of all the isolates used in this study was constructed using their Mash distances along with publicly available C. botulinum reference sequences and sequences of other $C$. botulinum type B isolates from the CDC collection. As indicated in Figure 1, 17 isolates harboring bont/B5 gene, including the wound isolate (CDC61035), formed their own cluster away from other bont/B5 harboring strains. The MLST analysis revealed that these 17 isolates belonged to ST-36. The other isolate harboring bont/B5 gene, CDC65069, clustered just outside the other 17 isolates and belonged to ST-104. These two sequence types, ST-36 and ST-104, differ at the recA and hsp loci. These results show that seven-gene MLST and MASH tree clustering provided congruent subtyping results.

One C. botulinum type B isolated from an infant botulism case from Hawaii (CDC48611) and the C. botulinum type B isolated from an infant botulism case from California (CDC21601) were determined to be subtype bont/B1. Both isolates clustered together and away from isolates harboring bont/B5 gene. The seven-gene MLST analysis showed CDC48611 as belonging to ST110 and CDC21601 as belonging to ST30. These two sequence types differ by only one locus, at aceK. Based on these limited data, it is unclear whether isolates harboring bont/B1 are common within Hawaii or whether the Hawaii bont/B1 case was due to travel from mainland United States.

LYVE-Set was used to approximate the phylogeny among the $18 \mathrm{C}$. botulinum isolates from Hawaii harboring bont/B5 gene (Figure 2). LYVE-Set resulted in two separate clades: one consisting of 17 isolates with 4-29 high -quality SNP differences among them; all these isolates belong to MLST ST-36. The small number of SNPs observed among members of clade 1 indicates a high homology. Clade 2 was separated from clade 1 by 10,103 high-quality SNPs, with only one member, CDC65069, which belongs to ST-104. The LYVE-set results indicate a high homology between the wound isolate (CDC61035) and the other isolates from infant botulism cases, which suggests that the C. botulinum type B isolated from a wound botulism case is closely related to other $C$. botulinum isolates present in the environment in Hawaii.

Attempts to identify how BTH becomes contaminated with C. botulinum spores have been unsuccessful. Previous studies conducted by the California Department of Public Health suggest that contamination of BTH with C. botulinum spores may occur during the cutting and diluting process (Passaro et al., 1998), and a study by Peak et al. suggests that BTH is typically cut where it is distributed (Peak et al., 2019). The Hawaii Drug Threat Assessment indicates that Oahu is the point of entry for Hawaii and is also a major distribution hub. It is also suggested that heroin is cut in Oahu before supplying to sellers and/or users (National Drug Intelligence Center, 2002).

The geographic distribution of C. botulinum isolates used in this study is relatively broad. Figure 3 shows the percentage of isolates used in the study per Hawaiian island. Oahu had the highest representation of isolates from infant botulism cases used in this study, and it was also the origin of the wound isolate (CDC61035). The close phylogenetic relationship between the C. botulinum type B isolated from the wound botulism case and the isolates from local infant botulism cases and the geographic distribution of these isolates in Hawaii strongly supports the hypothesis that this wound botulism case from Hawaii was due to locally acquired $C$. botulinum spores rather than from contamination during $\mathrm{BTH}$ production from a distant source.

\section{DATA AVAILABILITY STATEMENT}

The datasets presented in this study can be found in online repositories. The names of the repository/repositories and accession number(s) can be found in the article/ Supplementary Material.

\section{ETHICS STATEMENT}

The studies involving human participants were reviewed and approved by CDC Institutional Review Board. Written informed consent for participation was not required for this study in accordance with the national legislation and the institutional requirements.

\section{AUTHOR CONTRIBUTIONS}

$\mathrm{JH}$ and $\mathrm{CL}$ conceived the study. $\mathrm{JH}$ and $\mathrm{VF}$ performed the sequencing and data analysis. JD performed the original microbiology and identification of strains. KC-S provided the epidemiological review. All authors contributed to the article and approved the submitted version.

\section{ACKNOWLEDGMENTS}

Centers for Disease Control and Prevention, Center for Preparedness Response kindly provided support for this project. The findings and conclusions in this report are those of the authors and do not necessarily represent the views of the Centers for Disease Control and Prevention.

\section{SUPPLEMENTARY MATERIAL}

The Supplementary Material for this article can be found online at: https://www.frontiersin.org/articles/10.3389/fmicb.2021. 678473/full\#supplementary-material 


\section{REFERENCES}

Andrews, S. (2010). FastQC A Quality Control Tool for High Throughput Sequence Data [Online]. Available online at: http://www.bioinformatics.babraham.ac.uk/ projects/fastqc/ (accessed 2020).

Bankevich, A., Nurk, S., Antipov, D., Gurevich, A. A., Dvorkin, M., Kulikov, A. S., et al. (2012). SPAdes: a New Genome Assembly Algorithm and Its Applications to Single-Cell Sequencing. J. Comput. Biol. 19, 455-477. doi: 10.1089/cmb.2012. 0021

Barash, J. R., and Arnon, S. S. (2014). A novel strain of Clostridium botulinum that produces type B and type H botulinum toxins. J. Infect. Dis. 209, 183-191. doi: 10.1093/infdis/jit449

Brunt, J., Carter, A. T., Stringer, S. C., and Peck, M. W. (2018). Identification of a novel botulinum neurotoxin gene cluster in Enterococcus. FEBS Lett. 592, 310-317. doi: 10.1002/1873-3468.12969

Centers for Disease Control and Prevention (CDC) (1998). Botulism In The United States (1899-1996). Handbook For Epidemiologists, Clinicians, And Laboratory Workers. Atlanta: U.S. Department of Health and Human Services, CDC.

Chin, J., Arnon, S. S., and Midura, T. F. (1979). Food and environmental aspects of infant botulism in California. Rev. Infect. Dis. 1, 693-697. doi: 10.1093/clinids/ 1.4 .693

Davis, L. E., and King, M. K. (2008). Wound botulism from heroin skin popping. Curr. Neurol. Neurosci. Rep. 8, 462-468. doi: 10.1007/s11910-008-0074-2

Fleck-Derderian, S., Shankar, M., Rao, A. K., Chatham-Stephens, K., Adjei, S., Sobel, J., et al. (2017). The Epidemiology of Foodborne Botulism Outbreaks: a Systematic Review. Clin. Infect. Dis. 66, S73-S81.

Franciosa, G., Maugliani, A., Scalfaro, C., and Aureli, P. (2009). Evidence that plasmid-borne botulinum neurotoxin type B genes are widespread among Clostridium botulinum serotype B strains. PLoS One 4:e4829. doi: 10.1371/ journal.pone.0004829

Goris, J., Konstantinidis, K. T., Klappenbach, J. A., Coenye, T., Vandamme, P., and Tiedje, J. M. (2007). DNA-DNA hybridization values and their relationship to whole-genome sequence similarities. Int. J. Syst. Evol. Microbiol. 57, 81-91. doi: 10.1099/ijs.0.64483-0

Gurevich, A., Saveliev, V., Vyahhi, N., and Tesler, G. (2013). QUAST: quality assessment tool for genome assemblies. Bioinformatics 29, 1072-1075. doi: 10.1093/bioinformatics/btt086

Hill, K. K., Smith, T. J., Helma, C. H., Ticknor, L. O., Foley, B. T., Svensson, R. T., et al. (2007). Genetic diversity among Botulinum Neurotoxinproducing clostridial strains. J. Bacteriol. 189, 818-832. doi: 10.1128/jb. 01180-06

Jacobson, M. J., Lin, G., Raphael, B., Andreadis, J., and Johnson, E. A. (2008). Analysis of neurotoxin cluster genes in Clostridium botulinum strains producing botulinum neurotoxin serotype A subtypes. Appl. Environ. Microbiol. 74, 2778-2786. doi: 10.1128/aem.02828-07

KAPA Biosystems. (2016). KAPA Library Preparation Kit; Ion Torrent Platforms. Wilmington: KAPA Biosystems.

Katz, L. S., Griswold, T., Morrison, S., Caravas, J., Zhang, S., Bakker, H., et al. (2019). Mashtree: a rapid comparison of whole genome sequence files. J. Open Source Softw. 4:1762. doi: 10.21105/joss.01762

Katz, L. S., Griswold, T., Williams-Newkirk, A. J., Wagner, D., Petkau, A., Sieffert, C., et al. (2017). A Comparative Analysis of the Lyve-SET Phylogenomics Pipeline for Genomic Epidemiology of Foodborne Pathogens. Front. Microbiol. 8:375. doi: 10.3389/fmicb.2017.00375

Kenri, T., Sekizuka, T., Yamamoto, A., Iwaki, M., Komiya, T., Hatakeyama, T., et al. (2014). Genetic characterization and comparison of Clostridium botulinum isolates from botulism cases in Japan between 2006 and 2011. Appl. Environ. Microbiol. 80, 6954-6964. doi: 10.1128/aem.021 34-14
Life Technologies (2017). Ion 520 \& Ion 530 Kit - Chef USER GUIDE Revision D.0 [Online]. Thermo Fisher Scientific. Available online at: https://assets.thermofisher.com/TFS-Assets/LSG/manuals/MAN0010846_ Ion_520_530_Kit_Chef_UG.pdf (Accessed August 9, 2018).

Life Technologies (2019). Ion $510^{T M}$ \& Ion $520^{T M}$ \& Ion $530^{T M}$ Kit - Chef USER GUIDE. Instructions for automated template preparation, chip loading, and sequencing. Carlsbad: Life Technologies Corporation.

Luquez, C., Raphael, B. H., and Maslanka, S. E. (2009). Neurotoxin gene clusters in Clostridium botulinum type Ab strains. Appl. Environ. Microbiol. 75, 60946101. doi: 10.1128/aem.01009-09

Mansfield, M. J., Adams, J. B., and Doxey, A. C. (2015). Botulinum neurotoxin homologs in non-Clostridium species. FEBS Lett. 589, 342-348. doi: 10.1016/j. febslet.2014.12.018

National Drug Intelligence Center. (2002). Hawaii Drug Threat Assessment. Pennsylvania: National Drug Intelligence Center.

Nevas, M., Lindstrom, M., Virtanen, A., Hielm, S., Kuusi, M., Arnon, S. S., et al. (2005). Infant botulism acquired from household dust presenting as sudden infant death syndrome. J. Clin. Microbiol. 43, 511-513. doi: 10.1128/jcm.43. 1.511-513.2005

Ondov, B. D., Treangen, T. J., Melsted, P., Mallonee, A. B., Bergman, N. H., Koren, S., et al. (2016). Mash: fast genome and metagenome distance estimation using MinHash. Genome Biol. 17:132.

Passaro, D. J., Werner, S. B., Mcgee, J., Mac Kenzie, W. R., and Vugia, D. J. (1998). Wound botulism associated with black tar heroin among injecting drug users. JAMA 279, 859-863. doi: 10.1001/jama.279.11.859

Peak, C. M., Rosen, H., Kamali, A., Poe, A., Shahkarami, M., Kimura, A. C., et al. (2019). Wound Botulism Outbreak Among Persons Who Use Black Tar Heroin - San Diego County, California, 2017-2018. MMWR Morb. Mortal. Wkly. Rep. 67, 1415-1418. doi: 10.15585/mmwr.mm675152a3

Peck, M. W., Smith, T. J., Anniballi, F., Austin, J. W., Bano, L., Bradshaw, M., et al. (2017). Historical Perspectives and Guidelines for Botulinum Neurotoxin Subtype Nomenclature. Toxins 9:38. doi: 10.3390/toxins9010038

Popoff, M. R. (2018). Botulinum Neurotoxins: still a Privilege of Clostridia?. Cell Host Microbe 23, 145-146. doi: 10.1016/j.chom.2018.01.014

Rossetto, O., Pirazzini, M., and Montecucco, C. (2014). Botulinum neurotoxins: genetic, structural and mechanistic insights. Nat. Rev. Microbiol. 12, 535-549. doi: $10.1038 /$ nrmicro3295

United States Department of Justice Drug Enforcement Administration Office of Diversion Control. (2006). Practitioner's Manual: An Informational Outline of the Controlled Substances Act. Washington: United States Department of Justice.

Werner, S. B., Passaro, D., Mcgee, J., Schechter, R., and Vugia, D. J. (2000). Wound botulism in California, 1951-1998: recent epidemic in heroin injectors. Clin. Infect. Dis. 31, 1018-1024. doi: 10.1086/318134

Williamson, C. H., Sahl, J. W., Smith, T. J., Xie, G., Foley, B. T., Smith, L. A., et al. (2016). Comparative genomic analyses reveal broad diversity in botulinum toxin-producing Clostridia. BMC Genomics 17:180. doi: 10.1186/s12864-0162502-z

Conflict of Interest: The authors declare that the research was conducted in the absence of any commercial or financial relationships that could be construed as a potential conflict of interest.

Copyright (c) 2021 Halpin, Foltz, Dykes, Chatham-Stephens and Lúquez. This is an open-access article distributed under the terms of the Creative Commons Attribution License (CC BY). The use, distribution or reproduction in other forums is permitted, provided the original author(s) and the copyright owner(s) are credited and that the original publication in this journal is cited, in accordance with accepted academic practice. No use, distribution or reproduction is permitted which does not comply with these terms. 